\title{
FREQUENCY OF GENITAL TUBERCULOSIS IN PATIENTS UNDERGOING DIAGNOSTIC LAPAROSCOPY FOR INFERTILITY
}

\author{
Hina Niaz ${ }^{1}$, Asaf Alam Khan ${ }^{2}$
}

\section{$\underline{\text { ABSTRACT: }}$}

OBJECTIVES:

To determine the frequency of genital tuberculosis in patients undergoing diagnostic laparoscopy for infertility.

\section{METHODOLOGY:}

It is a descriptive (cross-sectional) prospective study. The study was performed within the duration of six months i.e., February 12 $2^{\text {th }}, 2020$ to August 12 2020 at the Department of Obstetrics and Gynecology, Khyber Teaching Hospital, Peshawar. A total of 196 patients were observed by using 47.1\% proportion of genital tuberculosis in infertility, 95\% confidence interval with margin of error 7\%, using software of WHO for sample size calculation. Further, sample collection was performed using non-probability (consecutive) sampling techniques.

\section{RESULTS:}

The mean age of the patients in our study was 30 years (SD+3.92). Fifty seven percent of cases were having primary infertility and $43 \%$ of patients were having secondary infertility. The incidence of genital tuberculosis undergoing infertility was $45 \%$.

\section{CONCLUSION:}

Our study concludes that the incidence of genital TB in infertility in our setup was $45 \%$.

KEYWORDS: Genital Tuberculosis, Laparoscopy, Infertility

How to cite this article:

Niaz H, Khan AA. Frequency of Genital Tuberculosis in Patients Undergoing Diagnostic Laparoscopy for Infertility. J Gandhara Med Dent Sci. $2022 ; 9(1): 49-52$

https://doi.org/10.37762/jgmds.9-1.182

\section{Correspondence:}

${ }^{1}$ Hina Niaz, Senior Registrar, Department of Gynaecology and Obstetrics, Khyber Teaching Hospital, MTI, Peshawar (8): $+92-332-9265356$

凶: drhinaniaz11@yahoo.com

${ }^{2}$ Trainee Registrar, Department of Cardiology, Khyber Teaching Hospital, MTI, Peshawar

\section{INTRODUCTION:}

Infertility is defined as inability to conceive during one year of regular, unprotected intercourse ${ }^{1,2}$. This issue is of global proportions and around 60-80 million people all over the world suffer from infertility $^{3,4}$. Incidence of infertility in developed communities is reported on a rise from those in developing countries ${ }^{5,6}$. Tuberculosis is considered among the major causes of infertility on a global basis along with post abortion and postpartum infections ${ }^{7}$. An accurate diagnosis is the first step towards successful treatment. The role of new and advanced procedures like laparoscopy needs to be established for evaluation of infertility in order to get benefit of this procedure ${ }^{8,9}$. Diagnostic laparoscopy is the standard method proceeded as the ultimate test in the infertility work up before advancing to infertility treatment ${ }^{10,11}$. A number of researches have shown that diagnostic laparoscopy is an effective procedure for assessment of long standing infertility. Laparoscopy reports unusual findings in $21.68 \%$ of cases and can be used for work up of the various reasons of female infertility. One of the key health problems among women affecting the quality of their life is infertility. It leads to social and psychological upsets and is a major cause of depression along with a sense of insecurity to many couples. An abundance of research on genital tuberculosis (GTB) causing infertility around the world is available, with numerous studies have been conducted in low-pay 
nations, where GTB has tremendous effects on women $^{\text {es }}$ reproductive health ${ }^{12-16}$. Yet, no study was found on this issue in Pakistan. In fact, no single study was found that is conducted in Pakistan, which can present precise and concrete statistics about infertility, subfertility and their causes, particularly genital tuberculosis. This study has been carried out with the aim to investigate the frequency of genital tuberculosis among patients who are undergoing laparoscopy for diagnosing the causes for infertility in our local population. The main reason behind conducting this study is that it will be the first study in this country providing statistics about infertility and genital tuberculosis. Moreover, this study will also help in finding other causes and etiology of infertility and subfertility and the effectiveness of diagnostic laparoscopy in our locality. The results obtained from this study will be shared with various hospitals and health care institutions, which will help the medical practitioners to improve the diagnosis and treatment of infertility and genital tuberculosis causing it.

\section{METHODOLOGY:}

This prospective cross sectional descriptive study was conducted in the Department of Obstetrics and Gynecology, Khyber Teaching Hospital, Peshawar for six months from February $12^{\text {th }}, 2020$ to August $12^{\text {th }}, 2020$. A total sample size was 196 using $47.1 \%$ proportion of genital tuberculosis in infertility, confidence interval of $95 \%$ and $7 \%$ margin of error, using software of WHO for sample size calculation. Non-probability purposive sampling was the sampling technique. All women presenting with infertility (primary and secondary) undergoing laparoscopy with age from $18-40$ years were included. Women having symptoms indicative of pulmonary tuberculosis/extra pulmonary tuberculosis, those with endocrine problems, sexual disorders, autoimmune diseases, lungs diseases, human immuno deficiency virus co-infection and the females having diabetes mellitus, malnourishment and other medical issues like hypertension, peritoneal adhesions due to past abdominal surgeries and abnormalities in ovulations were exclusion criteria of this study. These cited conditions in exclusion criteria had acted as confounders and whenever included they introduced bias in the study results. The study was conducted after approval from the ethical board and research committee of the hospital. All cases matching the inclusion criteria based on clinical findings presented to the outpatient department (OPD) were included. The goal and advantages of study and the entire procedure of clinical and laparoscopic diagnosis was explained to the patients and a written informed consent was taken from all subject patients. Detailed history was taken from all patients and examinations performed by gynecologists. The clinical diagnosis of genital tuberculosis was made on the features of genital tract inflammation. From all patients $5 \mathrm{cc}$ blood was taken and sent to the laboratory under the supervision of a senior pathologist having experience of more than 10 years, who was the fellow of CPSP. Histopathological evidence of TB, acid-fast bacilli (AFB) on microscopy, positive AFB culture, positive polymerase chain reaction (PCR), and mantoux tests was performed in all subject women. Laparoscopy was performed under general anesthesia by the conventional three-puncture technique in all cases with clinically suspected genital tuberculosis. The laparoscopic diagnosis was based on commonly accepted visual findings. All the information and other demographic data like age along with clinical, laboratory and laparoscopy findings were also being recorded in given proforma. The data collected was analyzed through SPSS version 17. Mean \pm SD were calculated for continuous variables like age and duration of infertility. Frequency and percentage were calculated for categorical variables like primary infertility, secondary infertility, and genital tuberculosis. The genital tuberculosis was stratified among age, primary infertility, and secondary infertility to see the effect modification. Post stratification done by Chi square test keeping $\mathrm{p}$ value $<0.05$ as significant. Final outcomes were given as tables.

\section{RESULTS:}

Among 196 cases, $45 \%$ had genital tuberculosis. 73 (37\%) subjects were $15-25$ years (33 had genital tuberculosis), 59 (30\%) subjects were 26-30 years of age (26 had genital tuberculosis), 41 (21\%) subjects were $31-35$ years of age (18 had genital tuberculosis), and 23 (12\%) subjects were 36-40 years of age (11 had genital tuberculosis). Mean age was 30 years with $\mathrm{SD}+3.92 .57 \%$ of the sample size had primary type of infertility and $43 \%$ had secondary type of infertility.

Table 1: Duration of Infertility and Stratification of Genital Tuberculosis $(n=196)$

\begin{tabular}{|c|c|c|}
\hline \multirow{2}{*}{ Duration of Infertility } & \multicolumn{2}{|c|}{ Genital Tuberculosis } \\
\cline { 2 - 3 } & Yes & No \\
\hline$\leq 10$ Years & 60 & 73 \\
\hline$>10$ Years & 28 & 35 \\
\hline Total & 133 & 63 \\
\hline
\end{tabular}


Mean duration of infertility was 7 years with $\mathrm{SD}+1.81$. Chi square test applied, which showed Pvalue of 0.9300 .

Table 2: Stratification of Genital Tuberculosis with Type of Infertility ( $n=196)$

\begin{tabular}{|l|c|c|c|}
\hline $\begin{array}{c}\text { Genital } \\
\text { Tuberculosis }\end{array}$ & $\begin{array}{c}\text { Primary } \\
\text { Infertility }\end{array}$ & $\begin{array}{c}\text { Secondary } \\
\text { Infertility }\end{array}$ & Total \\
\hline Yes & 62 & 26 & 88 \\
\hline No & 50 & 58 & 108 \\
\hline Total & 112 & 84 & 196 \\
\hline
\end{tabular}

Chi square test applied, which showed P-value of 0.0007 .

\section{DISCUSSION:}

This study shows that mean age was 30 years with $\mathrm{SD}+3.92 .57 \%$ cases were having primary infertility while $43 \%$ patients were having secondary infertility. Incidence of genital tuberculosis in infertility in our setup was $45 \%$. Other studies showed the same results as female genital tuberculosis (GTB) is a common cause of infertility, affecting $58 \%$ of the cases. The global prevalence of GTB varies between developed and developing countries, predicted to be $8-10$ million cases with an increasing frequency. Sharma JB and fellows conducted a study on laparoscopic findings in female genital tuberculosis and found $47.1 \%$ cases of GTB causing infertility. Agrawal et al, ${ }^{7}$ directed a huge report involving 1,120 cases that are infertile and concluded that assessment through a laparoscope is an entirely significant device to find out the cause of tubal factor infertility. They found that GTB represented $63.6 \%$ cases of infertility involving fallopian tubes, and tubercular lesions found through a laparoscope were of following kinds: adherent masses $35.8 \%$, miliary ascites $9.4 \%$, adhesions, calcification (43.1\%), nodular sclerosis $(11.7 \%)$. Another group of scientists evaluated 7,628 patients in gynae OPD to determine the frequency of genital tuberculosis by performing culture and histopathologic tests. The investigators discovered $7 \%$ of outpatients were infertile and $2.3 \%$ cases having genital tuberculosis. They deduced that this is of prime importance for a gynecologist, especially in tuberculosis endemic nations, to envision the chance of pelvic tuberculosis in cases of infertility. Whereas, many researchers assessed the clinical utilization of Polymerase Chain Reaction in analysis of mycobacterial diseases ${ }^{17}$. Genital tuberculosis largely occurs due to hematogenous dissemination and uterine tubes are almost always affected, while endometrium is involved in $27-79 \%$ patients ${ }^{18}$. As all cases of salphingitis and endometriosis may not present together, salphingitis alone is mostly missed by the histopathological sample of endometrium for tuberculosis polymerase chain reaction but can be doubted by cautious but thorough endoscopic evaluation for the existence of tubercles, peritubal and periovarian adhesions, and cornual and fimbrial block. Another explanation to clarify the large falsepositive rate of endoscopic evaluation is that these subjects may have taken antitubercular drugs for extra genital/genital tuberculosis and these patients do not reveal the history because either the drugs were given in their early age about which they do not know or these patients hide the treatment due to social stigma related to tuberculosis. These circumstances are common in nations not fully developed like India, where infertile cases generally experience extensive social pressure to get pregnant, ${ }^{19}$ and confront the absence of family knowledge regarding tuberculosis. Another explanation is, the findings of hydrosalpinx, blocked tubes, and tub ovarian masses and adhesions may be the consequence of gonococcal/pyogenic bacilli infection, and can clarify the negative polymerase chain reaction in cases with endoscopic abnormal findings indicating tuberculosis ${ }^{20}$.

\section{CONCLUSION:}

Our study presumes that the frequency of genital tuberculosis in infertility in our setup was $45 \%$.

\section{CONFLICT OF INTEREST: None}

\section{FUNDING SOURCES: None}

\section{REFERENCES:}

1. Gad MS, Dawood RM, Antar MS, Ali SE. Role of hysteroscopy and laparoscopy in evaluation of unexplained infertility. Menoufia Med J. 2019;32(4):1401-5.

2. Dogra A, Kaul I, Kanta S. Endometrial tuberculosis pick by PCR; in female infertility. JK Sci. 2019;21(1):21-5.

3. Babakhanzadeh E, Nazari M, Ghasemifar $\mathrm{S}$, Khodadadian A. Some of the factors involved in male infertility: a prospective review. Int J Gen Med. 2020;13:29-41.

4. Wasilewski T, Łukaszewicz-Zając M, Wasilewska J, Mroczko B. Biochemistry of infertility. Clin Chim Acta. 2020;508:18590.

5. Messinis IE, Messini CI, Daponte A, Garas A, Mahmood T. The current situation of infertility services provision in Europe. Eur 
J Obstet Gynecol Reprod Biol. 2016;207:200-4.

6. Messini CI, Daponte A, Anifandis G, Mahmood T, Messinis IE. Standards of care in infertility in Europe. Eur J Obstet Gynecol Reprod Biol. 2016;207:205-10.

7. Agrawal M, Roy P, Bhatia V, Dutt S, Gaur R. Role of microbiological tests in diagnosis of genital tuberculosis of women with infertility: a view. Indian J Tuberc. 2019;66(2):234-9.

8. Yu X, Cai H, Guan J, Zheng X, Han H. Laparoscopic surgery: any role in patients with unexplained infertility and failed in vitro fertilization cycles?. Medicine. 2019;98(13):e14957.

9. Kutubi A, Rahman R, Rahman S, Rahman MM. Evaluation of female infertility by laparoscopy in a secondary level infertility care centre. J Shaheed Suhrawardy Med Coll. 2019;11(1):9-12.

10. Madhuri N, Rashmi HS, Sujatha MS, Dhanyata G. Role of diagnostic hysterolaproscopy in the evaluation of female infertility. Int $\mathrm{J}$ Res Med Sci. 2019;7(5):1531.

11. Chanu SM, Pal GSR, Panda S, Singh AS. Diagnostic hysterolaparoscopy for evaluation of infertility: our experience in a tertiary care hospital. J Hum Reprod Sci. 2018;11(1):19-23.

12. Agarwal N, Gupta M, Agrawal A. Evaluation of genital tuberculosis as a cause of female infertility in a tertiary care hospital in North India. Int J Community Med Public Health. 2019;6:386.

13. Verma S, Tamrakar VK, Dewangan S, Madhariya N. Study to find out the incidence of genital tuberculosis is a cause of female infertility in Chhattisgarh India. Int Multidiscip Res J. 2019;9(7):12-6.
14. Mchunu M, Seevnarain D, Naicker K, Morapedi M, Memo N, Sebitloane HM. Female genital tract tuberculosis: a case report. Obstet Gynaecol Forum. 2019;29(3):31-2.

15. Djuwantono T, Permadi W, Septiani L, Faried A, Halim D, Parwati I. Female genital tuberculosis and infertility: serial cases report in Bandung, Indonesia and literature review. BMC Res Notes. 2017;10(683):1-7.

16. Naik SN, Chandanwale A, Kadam D, Sambarey PW, Dhumal G, DeLuca A, et al. Detection of genital tuberculosis among women with infertility using best clinical practices in India: an implementation study. Indian J Tuberc. 2021;68(1):85-91.

17. Szekely J, Chelae S, Ingviya N, Rukchang W, Auepemkiate S, Aiempanakit K. Universal Multiplex Polymerase Chain Reaction-Restriction Fragment Length Polymorphism (UMPCR-RFLP) for rapid detection and species identification of fungal and mycobacterial pathogens. Walailak J Sci Technol. 2020;17(10):111325.

18. Gupta S, Gupta P. Etiopathogenesis, challenges and remedies associated with female genital tuberculosis: potential role of nuclear receptors. Front Immunol. 2020;11:02161.

19. Rai R, Rai AK. Sexual violence and poor mental health of women: an exploratory study of Uttar Pradesh, India. Clin Epidemiol Global Health. 2020;8:194-8.

20. Saha AK, Suresh A, Eipe T, Nair N. Hydrosalpinx with adhesion colic: a case report. Ann Rom Soc Cell Biol. 2021:9489-91.

\section{CONTRIBUTORS}

1. Hina Niaz - Concept \& Design; Data Acquisition; Data Analysis/Interpretation; Supervision; Final Approval 2. Asaf Alam Khan - Drafting Manuscript; Critical Revision

LICENSE: JGMDS publishes its articles under a Creative Commons Attribution Non-Commercial Share-Alike license (CC-BY-NC-SA 4.0) COPYRIGHTS: Authors retain the rights without any restrictions to freely download, print, share and disseminate the article for any lawful purpose. It includes scholarly networks such as Research Gate, Google Scholar, LinkedIn, Academia.edu, Twitter, and other academic or professional networking sites. 